\title{
U⿱宀⿻三丨口
}

\section{Explaining Away and the Cognitive Science of Religion}

Glass, D. H. (2016). Explaining Away and the Cognitive Science of Religion. Theology and Science, 14(3), 288304. https://doi.org/10.1080/14746700.2016.1191879

Link to publication record in Ulster University Research Portal

\section{Published in:}

Theology and Science

Publication Status:

Published online: 18/08/2016

DOI:

10.1080/14746700.2016.1191879

\section{Document Version}

Author Accepted version

\section{General rights}

Copyright for the publications made accessible via Ulster University's Research Portal is retained by the author(s) and / or other copyright owners and it is a condition of accessing these publications that users recognise and abide by the legal requirements associated with these rights.

\section{Take down policy}

The Research Portal is Ulster University's institutional repository that provides access to Ulster's research outputs. Every effort has been made to ensure that content in the Research Portal does not infringe any person's rights, or applicable UK laws. If you discover content in the Research Portal that you believe breaches copyright or violates any law, please contact pure-support@ulster.ac.uk. 


\title{
Explaining Away and the Cognitive Science of Religion
}

\author{
David H. Glass \\ School of Computing and Mathematics, University of Ulster, \\ Newtownabbey, Co. Antrim, BT37 0QB, UK
}

\begin{abstract}
In order to evaluate the claim that theistic belief can be explained away by science, four models of the relationship between science and theism are developed and their relevance to explaining away explored. These models are then used to evaluate an argument against theistic belief based on developments in the cognitive science of religion. It is argued that even if the processes that produce theistic belief are unreliable, this is insufficient to show that explaining away takes place. Indeed, given the difficulty of showing that the conditions for explaining away are met, it is very unlikely that such an argument can succeed.
\end{abstract}

Keywords: Explanation, Explaining away, Cognitive Science of Religion, Evolutionary Debunking Arguments, Bayesian reasoning, Models of Science and Religion.

\section{Introduction}

Explaining away arguments are very common in popular discussions about the relationship between science and God. Roughly speaking, the idea is that science not only explains features of the natural world, but that in doing so it also explains away God. Perhaps God was needed in the past to help us make sense of the world, but now science has provided alternative, better explanations. While science does not logically rule out God's existence, it makes God redundant since there is no need for two explanations (God and science) when one (science) will do. Following Laplace, we no longer have need of the God hypothesis.

Appealing as this line of reasoning might be, it cannot simply be assumed that only one explanation is needed, and so that explaining away occurs, without begging the question. If there are two suspects, Smith and Jones, for a particular crime, can it be assumed that if Smith is guilty then Jones is not? The answer is clearly no, as this will depend on such factors as whether Smith's guilt would, on its own, account for all the relevant evidence and whether Smith and Jones typically work together.

Criteria would be needed to determine whether explaining away occurs in a given context and this issue has been addressed using probability theory in both the artificial intelligence literature and in philosophy in the context of design arguments. ${ }^{1}$ In another paper, informal questions based on the formal approach were identified to help to determine whether explaining away occurs in a particular case and this approach was then applied to several science-religion debates. ${ }^{2}$ In the current volume, Rodney Holder applies this approach to contemporary debates in cosmology. ${ }^{3}$ 
This paper explores explaining away in the context of cognitive science of religion (CSR). There has been a lot of discussion in this area about so-called debunking arguments which claim that scientific explanations of religious belief undermine the rationality of religious belief. Before addressing this issue, a brief review of explaining away will be presented; then four probabilistic models of the relationship between science and theism will be discussed and their relevance to explaining away explored. This work will then provide a foundation for addressing a debunking argument based on CSR.

\section{Review of Explaining Away}

Suppose that your car will not start. One possible explanation is that the battery is flat; another, that there is a fault with the starter motor. If an investigation reveals that the battery is indeed flat, this means that there is no longer any reason to think that there is a problem with the starter motor. Notice that the two hypotheses are compatible with each other. This means you could be very unlucky: there could be a problem with the battery and the starter motor. However, based on the evidence of the car not starting and the fact that the battery is flat, any reason for inferring a problem with the starter motor has gone. There is no need to infer two explanations (flat battery and faulty starter motor) when one will do (flat battery). The flat battery hypothesis has explained away the evidence for the faulty starter motor hypothesis.

This scenario provides a simple example of explaining away, but it cannot be assumed that one explanation always removes the need for another explanation. The conditions under which explaining away occurs need to be determined. Previous work addressed this problem using a Bayesian approach and will now be reviewed briefly. ${ }^{4}$

Consider a piece of evidence $\mathrm{E}$ and two hypotheses $\mathrm{T}$ and $\mathrm{S}$ that provide explanations of $\mathrm{E}$. Suppose that $\mathrm{E}$ increases the probability of (or confirms) $T$, i.e. $\mathrm{P}(\mathrm{T} \mid \mathrm{E})>\mathrm{P}(\mathrm{T})$. If the other hypothesis $\mathrm{S}$ is discovered to be true, what effect does that have on the initial hypothesis $\mathrm{T}$ ? If the probability of $\mathrm{T}$ after both $\mathrm{S}$ and $\mathrm{E}$ are taken into account is lower than it was after only $\mathrm{E}$ was taken into account, then we say that 'S explains away the evidence $\mathrm{E}$ for $\mathrm{T}$ ' or when the evidence $\mathrm{E}$ is taken for granted, ' $\mathrm{S}$ explains away $\mathrm{T}$ '. Hence the condition for explaining away is: $:^{5,6}$

$$
\mathrm{P}(\mathrm{T} \mid \mathrm{S} \& \mathrm{E})<\mathrm{P}(\mathrm{T} \mid \mathrm{E})
$$

To make things more relevant to the present context, let $\mathrm{T}$ represent Theism, $\mathrm{S}$ represent Science and $\mathrm{E}$ the evidence of the natural world for which both theism and science might be considered to provide explanations. Supposing that $\mathrm{E}$ is taken into account to obtain the probability of theism $\mathrm{T}$ given $\mathrm{E}, \mathrm{P}(\mathrm{T} \mid \mathrm{E})$, then explaining away occurs if accepting science $\mathrm{S}$ in addition to the evidence $\mathrm{E}$ lowers the probability of $\mathrm{T}$. 
Suppose that $\mathrm{T}$ and $\mathrm{S}$ are independent of each other to begin with, i.e. $\mathrm{P}(\mathrm{S} \mid \mathrm{T})=\mathrm{P}(\mathrm{S})$. In this case explaining away can be shown to occur if:

$$
\mathrm{P}(\mathrm{E} \mid \mathrm{T} \& \mathrm{~S}) \times \mathrm{P}(\mathrm{E} \mid \sim \mathrm{T} \& \sim \mathrm{S})<\mathrm{P}(\mathrm{E} \mid \sim \mathrm{T} \& \mathrm{~S}) \times \mathrm{P}(\mathrm{E} \mid \mathrm{T} \& \sim \mathrm{S})
$$

Explaining away in this case occurs along an indirect pathway via the evidence; $\mathrm{T}$ and $\mathrm{S}$ have no direct bearing on one another, but in light of the evidence $\mathrm{E}$, learning that one hypothesis is true weakens the case for the other. This is how explaining away occurs in the car example. Assuming a flat battery has no bearing on whether there is a problem with the starter motor before the evidence (of the car not starting) is taken into account, it does have a bearing on it afterwards (it explains it away) due to the fact that it explains the evidence.

If $\mathrm{T}$ and $\mathrm{S}$ are not independent then explaining away can be shown to occur if:

$$
\mathrm{P}(\mathrm{E} \mid \mathrm{T} \& \mathrm{~S}) \times \mathrm{P}(\mathrm{E} \mid \sim \mathrm{T} \& \sim \mathrm{S}) \times \mathrm{P}(\mathrm{S} \mid \mathrm{T}) \times \mathrm{P}(\sim \mathrm{S} \mid \sim \mathrm{T})<\mathrm{P}(\mathrm{E} \mid \sim \mathrm{T} \& \mathrm{~S}) \times \mathrm{P}(\mathrm{E} \mid \mathrm{T} \& \sim \mathrm{S}) \times \mathrm{P}(\mathrm{S} \mid \sim \mathrm{T}) \times \mathrm{P}(\sim \mathrm{S} \mid \mathrm{T})
$$

In this case, in addition to the indirect pathway, $\mathrm{T}$ and $\mathrm{S}$ can influence each other via a direct pathway, i.e. if there is a positive or negative dependence between them before the evidence E is taken into account. In the car example, this would be the case if, for example, having a flat battery caused a problem with the starter motor or else somehow ensured that the starter motor was working properly. Typically, both the direct and indirect pathways need to be taken into account to determine whether explaining away occurs.

The direct and indirect pathways are closely related to epistemological relations of defeat. ${ }^{7}$ If the only influence between the hypotheses is a negative dependence along the direct pathway, then learning that one hypothesis is true would make the other less likely to be true and hence would constitute what is called a rebutting defeater for it. Similarly, a negative dependence along the indirect pathway is closely related to the relation of undercutting defeat. For example, the fact that the car does not start provides some reason to believe that there is a problem with the starter motor, but discovering that the battery is flat provides an undercutting defeater for that belief, i.e. it undercuts the reason for believing it. So explaining away could be thought of as a kind of explanatory defeat that combines both types of defeaters. However, approaching the issue in terms of explaining away seems to have some advantages since both pathways need to be taken into account to get a clear picture and the Bayesian approach provides a suitable framework for combining the influences from both pathways and for establishing the conditions under which explaining away occurs. ${ }^{8}$

Above, and in previous work, it has been assumed that the evidence confirms $\mathrm{T}$ so that $\mathrm{P}(\mathrm{T} \mid \mathrm{E})$ $>\mathrm{P}(\mathrm{T})$, but even if that is not the case it still makes sense to say that $\mathrm{S}$ explains away $\mathrm{T}$ if the relevant conditions are satisfied. For example, some will doubt that the existence of complex life really confirmed theism before Darwin, but will still wish to maintain that evolution removes the need for God and hence explains away theism to at least some extent. 


\section{Four models of the relationship between theism and science}

In the literature on science and religion, various typologies or models of the relationship between them are often discussed. These models help us to conceptualize different ways of thinking about how science and religion can be related and how a range of topics might be approached from the perspective of the different models. Perhaps the best known classification is Ian Barbour's fourfold typology consisting of i) conflict, ii) independence, iii) dialogue, and iv) integration. ${ }^{9}$

Here too, four models are considered, but the goal is to characterize different probabilistic relationships between theism (T), science $(\mathrm{S})$ and the evidence $(\mathrm{E})$ for which both theism and science might be thought to provide explanations. Some of these models correspond to recognizable ways of thinking about how science and religion relate to each other that have been discussed elsewhere in the literature, but the purpose here is to provide a framework for thinking about explaining away that can then be used to address explaining away in the context of CSR.

Figure 1 illustrates four ways in which T, S and E might be related. These relationships are represented using simple Bayesian networks where the absence of an edge between two nodes represents an independence relationship. ${ }^{10}$ Each of the four models, including the independence relationships, will be explained and discussed in turn.

\section{Independence Model}

In model 1 in figure 1(a), there is a probabilistic dependence between science and the evidence $\mathrm{E}$ (which will be assumed to be positive), but theism is independent of science and E. In this case, E does not provide any evidence for theism in the first place and science has no effect on theism either. In probabilistic terms, $\mathrm{P}(\mathrm{T} \mid \mathrm{E} \& S)=\mathrm{P}(\mathrm{T} \mid \mathrm{E})=\mathrm{P}(\mathrm{T})$ and hence explaining away cannot occur if this model is correct. Still, this highlights a response that some theists might offer to explaining away arguments. They will claim that it is a mistake to think of theism in terms of providing explanations for features of the natural world that might be amenable to scientific explanation and that science itself has no bearing on the existence of God. Such theists might reject all the arguments of natural theology, adopting some kind of fideism or perhaps argue that belief in God is properly basic, or they might appeal to the moral argument, for example, but whatever the case explaining away arguments have no force. For many theists, however, this response comes at too high a price since they wish to point to at least some features of the natural world as evidence for God. 

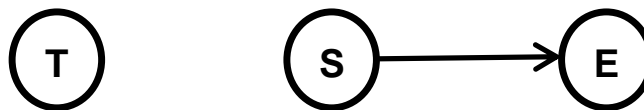

(a)

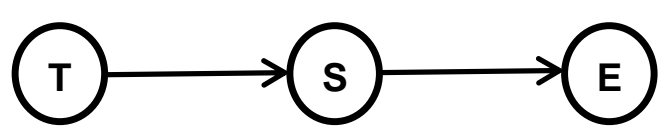

(b)

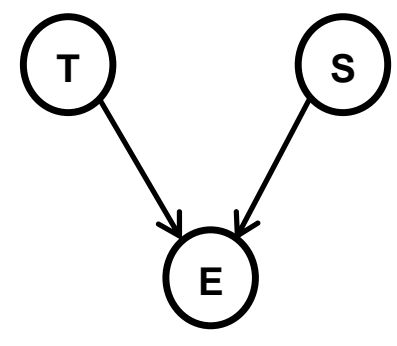

(c)

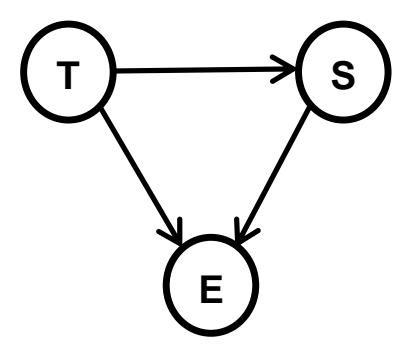

(d)

Figure 1. Simple Bayesian networks for four different models for the relationship between Theism, T, Science, S and Evidence, E. (a) In model $1 \mathrm{~T}$ is independent of $\mathrm{S}$ and E. (b) Model 2 represents a causal chain where $\mathrm{T}$ and $\mathrm{E}$ are independent given S. (c) In model $3 \mathrm{~T}$ and $\mathrm{S}$ are unconditionally independent, but can become dependent given $\mathrm{E}$. (d) In model 4 no independence relationships are assumed.

\section{Conditional Independence Model}

Figure 1(b) offers a second model for the relationship between T, S and E. This model differs from the first model in that theism is no longer considered to be independent of the evidence E. However, it is conditionally independent of E given science, i.e. $P(T \mid E \& S)=P(T \mid S)$, or equivalently it can be said that $\mathrm{S}$ screens off $\mathrm{T}$ from $\mathrm{E}$. Again, it can be assumed that the relationship between science and the evidence $\mathrm{E}$ is positive, $\mathrm{P}(\mathrm{E} \mid \mathrm{S})>\mathrm{P}(\mathrm{E})$, and let us assume for the moment that the relationship between science and theism is positive so that $\mathrm{P}(\mathrm{S} \mid \mathrm{T})>$ $\mathrm{P}(\mathrm{S})$. In this case $\mathrm{T}, \mathrm{S}$ and $\mathrm{E}$ can be said to form a causal chain in the sense that the 
probabilistic relationships between them are such as would typically be found in cases where $\mathrm{T}$ is a direct cause of $\mathrm{S}, \mathrm{S}$ is a direct cause of $\mathrm{E}$ and $\mathrm{T}$ is not a direct cause of $\mathrm{E}$. It is not clear what it means to say that science, S, causes evidence, E. However, if S is taken to represent scientific laws and the initial conditions of the universe, then this model would represent the idea that God acts indirectly in the world via secondary causes. In this case, it is easy to show that explaining away does not occur. First, note that the relationship between $\mathrm{S}$ and $\mathrm{T}$ can be expressed as $\mathrm{P}(\mathrm{T} \mid \mathrm{S})>\mathrm{P}(\mathrm{T} \mid \sim \mathrm{S})$. Given the screening off condition, this can be expressed as $\mathrm{P}(\mathrm{T} \mid \mathrm{E} \& S)>\mathrm{P}(\mathrm{T} \mid \mathrm{E} \& \sim \mathrm{S})$, from which it follows that $\mathrm{P}(\mathrm{T} \mid \mathrm{E} \& S)>\mathrm{P}(\mathrm{T} \mid \mathrm{E})$ and so it is clear that explaining away does not occur.

In the above discussion, it has been assumed that there is a positive direct relationship between science and theism, but that could be disputed. If it could be argued that there is a negative dependence, then the strategy for responding to explaining away arguments given above would not work. However, two important considerations need to be borne in mind. First, in this case it would not be the success of science in explaining the evidence that would lead to a problem for the theist, but rather the claim that science itself somehow directly undermines theism. In other words, explaining away would occur along the direct pathway; in this model, explaining away cannot occur along the indirect pathway via the evidence.

In the case of science and theism, it is not clear what type of argument could show that science directly undermines theism. This brings us to the second point, which is that there are clear arguments that would tend to support a positive dependence between theism and science. An obvious example is that the orderly, law-like behaviour that makes science possible can be explained by the existence of a rational Creator. The point here is not to defend this argument, but to suggest that there are at least as good grounds for arguing for a positive direct dependence between theism and science as there are for arguing for a negative dependence. And if that is correct, model 2 provides an excellent way to think about science that avoids explaining away arguments.

For many theists, this represents a very popular model for the relationship between science and theism. According to this model, it is the task of science to provide explanations for particular features of the natural world, but theism provides the context for science since it explains the existence of order in the universe, as expressed in the laws of nature, and why the universe is comprehensible.

Model 2 seems to offer a very plausible response to explaining away arguments since it shows why explaining away does not work, but does so without making theism irrelevant to science. However, it might be argued that God does not merely act via the laws of nature, but guides natural processes in some way. For this reason, models involving a direct influence from $\mathrm{T}$ to $\mathrm{E}$ will now be considered.

\section{Indirect Conflict Model}


Now consider model 3 in figure 1(c). Here, theism and science are considered to be independent before the evidence $\mathrm{E}$ is taken into account, but unlike model 1 there is a probabilistic dependence between theism and $\mathrm{E}$, which again can be taken to be positive so that when science is not taken into account E confirms theism. According to this model, it is very plausible to think that explaining away would occur since if theism and science are considered to offer reasonable explanations it seems likely that $\mathrm{P}(\mathrm{E} \mid \sim \mathrm{T} \& \sim \mathrm{S})$ would be very low and so inequality (2) in section 2 would be expected to hold. Furthermore, if either hypothesis on its own makes the evidence highly probable so that $\mathrm{P}(\mathrm{E} \mid \sim \mathrm{T} \& \mathrm{~S})$ and $\mathrm{P}(\mathrm{E} \mid \mathrm{T} \& \sim \mathrm{S})$ are both high, this again makes it likely that condition for explaining away would be satisfied. This model would be appropriate for the car example and so makes it clear why explaining away occurs in that case.

In response to this, theists could claim that certain features of the natural world would be very unlikely from a scientific point of view in an atheistic universe, i.e. $\mathrm{P}(\mathrm{E} \mid \sim \mathrm{T} \& \mathrm{~S})$ is very low. However, assuming this is still greater than $\mathrm{P}(\mathrm{E} \mid \sim \mathrm{T} \& \sim \mathrm{S})$, it seems likely that explaining away would still occur. ${ }^{11}$ Suffice it to say, model 3 provides the most significant scope for explaining away of the models considered so far.

Indeed, model 3 provides a way for thinking about how conflict can arise between science and theism even when there is no intrinsic incompatibility between them (or even negative dependence before the evidence is taken into account). And, of course, the conflict can occur in two opposing ways. Here the assumption has been that science should be accepted and given this model, science might weaken the evidential case for theism to some extent. Equally, however, it shows how theists embracing this indirect conflict model could come to reject science (or aspects of it) since explaining away is symmetric and so insofar as they believe they have good independent reasons to accept theism, this could undermine science to some extent. Arguably, this indirect conflict model captures much better the perception of conflict between science and theism adopted by some theists and atheists than any model based on an intrinsic, logical incompatibility.

\section{Interdependence Model}

Many theists will consider model 3 to be seriously limited since they will wish to argue that there is a positive dependence between science and theism as discussed in the context of the conditional independence model (model 2). Hence, for such theists, model 4 in figure 1(d) will seem preferable. This model is a hybrid between models 2 and 3 and can be described as an interdependence model since T, $\mathrm{S}$ and $\mathrm{E}$ are all interdependent and it allows theism and science to be related in two different ways (directly and indirectly via the evidence). Like model 3, explaining away cannot be ruled out in principle, but this can be offset by a direct positive dependence between $\mathrm{T}$ and $\mathrm{S}$. This model seems to capture the belief of many theists that God guides natural processes. It can also lead to additional support for theism compared with model 2 since evidence for theism from science need not be mediated solely through scientific theories. ${ }^{12}$ 


\section{Discussion}

Of the four models considered, it seems clear that there are plenty of options open to the theist to respond to explaining away arguments. Explaining away arguments will seem plausible if a framework such as model 3 is assumed, but it is far from clear that it is the best way to model the relationship between science and theism. Not surprisingly, this model seems to capture best how the New Atheists, such as Richard Dawkins, think about the relationship between science and theism. From the fact that science explains, it is often simply assumed, with no need for further argument, that it also explains away any need for God. It is also this model which gives rise to most conflict in the opposite direction, whereby theists might reject aspects of science.

For the theist, model 1 avoids any problems, but comes at too high a price for many theists since theism is made completely independent of science and the evidence of the natural world. Model 4 does not preclude explaining away, but it has plenty of resources for responding to it and it also allows for the possibility of additional evidence for theism over and above any mediated through scientific theories. Model 2 offers the most straightforward way for theists to counter explaining away arguments. According to it, theism and science provide explanations in a way that precludes explaining away unless it can be shown that science directly undermines theism.

This presents an enormous challenge for advocates of explaining away arguments. Merely pointing out how well science explains features of the natural world is completely inadequate and it is not at all clear how it could be shown that science directly undermines theism since there are plausible reasons for thinking that just the opposite is the case.

The different models provide general ways of thinking about the relationship between science and theism and about the topic of explaining away. They will now be used to help address the question of explaining away in the cognitive science of religion.

\section{Application to Cognitive Science of Religion (CSR)}

In recent years, there has been a lot of interest in CSR and evolutionary explanations for religious belief. The focus here is not on the details of the scientific explanations that have been proposed, but on their relevance for the rationality of religious belief. ${ }^{13}$ In this context, evolutionary debunking arguments aim to show that in light of evolutionary explanations of religious belief, such belief is irrational. ${ }^{14}$ As with evolutionary debunking arguments in general, ${ }^{15}$ the idea is that the processes that produce religious belief do not track truth and so even if no supernatural agents exist, people would still believe in them.

Before discussing how this argument relates to explaining away, it is worth commenting on the objection that arguments of this kind against religious belief commit the genetic fallacy: CSR identifies the processes that produce religious beliefs, but this is irrelevant to the 
justification of religious beliefs. In a very insightful article, Joshua Thurow provides two responses to this objection. ${ }^{16}$ First, CSR concerns not just the origin of religious beliefs, but the reasons why they are continually held. Second, suppose someone comes to the conclusion that religious beliefs were produced by unreliable processes without good evidence and she has no other reasons for her beliefs, then her beliefs would no longer be justified. Hence, the origin of a belief can be relevant for the justification of the belief.

With respect to the first point, even if cognitive science can explain why religious beliefs are currently held, that still seems like a separate issue from their justification. If there are good reasons for the truth of particular religious beliefs, that would provide a justification for their truth irrespective of the existence of processes that explain why people hold such beliefs. What this, together with Thurow's second point, suggests is that CSR might in principle be able to undermine the justification of religious beliefs if they are held in a basic way, i.e. without any independent reasons to support them. This is brought out clearly by Matthew Braddock (this volume), who argues that religious beliefs are not justified 'in the absence of independent evidence for their reliability'. Many will question whether religious beliefs held in a basic way could be justified at all, but this controversial view has been defended by Alvin Plantinga and other advocates of reformed epistemology. ${ }^{17}$ Thus, it seems plausible to view debunking arguments based on CSR as primarily targeting reformed epistemology or similar approaches to the rationality of religious belief. If this is correct, then an obvious strategy for religious believers is simply to accept that debunking arguments would work in the absence of independent reasons for their beliefs, but to maintain that there are in fact good reasons. ${ }^{18,19}$

How does this kind of argument relate to explaining away? First, the point just mentioned also applies to explaining away arguments. Even if an explaining away argument against theism is successful, this does not mean that theism is false or irrational, but just that it has been undermined in the specific context under consideration. Hence, other independent reasons for theism could mean that it is still justified overall despite the success of an explaining away argument. Another point of contact with explaining away is that debunking arguments from CSR appeal to the truth of a scientific explanation, but as the earlier discussion showed the move from the truth of a scientific explanation to the claim that theism is thereby undermined or explained away is not straightforward.

\section{Insensitivity and Explaining Away}

To consider the relationship with explaining away further, consider a common CSR debunking argument which appeals to the insensitivity of the processes that produce religious beliefs. ${ }^{20}$ These processes are said to be insensitive if they would still result in religious beliefs even if those beliefs were false (for example, if no supernatural agents existed). If they are insensitive in this way, it is argued that we should suspend judgment in the reliability of the processes that give rise to religious beliefs and as a consequence we are not justified in holding such beliefs. 
Let $\mathrm{T}$ represent the existence of one or more supernatural agents, $\mathrm{S}$ that some CSR account is correct, and E the fact that people believe in the existence of supernatural agents. One could question whether $S$ is true, but for the sake of argument we will assume that it is. ${ }^{21}$ In probabilistic terms, we can represent the insensitivity claim as $\mathrm{P}(\mathrm{E} \mid \mathrm{T} \& \mathrm{~S})=\mathrm{P}(\mathrm{E} \mid \sim \mathrm{T} \& \mathrm{~S})$ since the truth or falsity of $\mathrm{T}$ has no bearing on $\mathrm{E}$ if $\mathrm{S}$ is true. This can be distinguished from the claim that that a CSR account of religious belief (S) explains away belief in the existence of supernatural agents $(\mathrm{T})$ by explaining belief in such agents $(\mathrm{E})$, which can be expressed probabilistically as $\mathrm{P}(\mathrm{T} \mid \mathrm{S} \& \mathrm{E})<\mathrm{P}(\mathrm{T} \mid \mathrm{E})$, that $\mathrm{S}$ disconfirms $\mathrm{T}$ given $\mathrm{E}$. A key point in what follows is that even if the insensitivity claim is true, the explaining away claim need not be.

How does the insensitivity claim relate to the four models of the relationship between science and religion that we considered earlier? Interestingly, two of the models (1 and 2) already presuppose insensitivity. Model 1 will be considered later, but consider first the conditional independence model (model 2). According to this model, $\mathrm{T}$ and $\mathrm{E}$ are independent of each other given $\mathrm{S}$ and so the insensitivity claim holds. Does this lead to explaining away? This will be considered in the next subsection, but essentially it depends on whether there is a negative dependence between $\mathrm{T}$ and $\mathrm{S}$, i.e. on whether $\mathrm{P}(\mathrm{S} \mid \mathrm{T})<\mathrm{P}(\mathrm{S})$. If there is not, then explaining away cannot occur, as discussed in the previous section, since this would constitute a causal chain from $\mathrm{T}$ to $\mathrm{S}$ to $\mathrm{E}$. As also discussed there, this is a common way to think about the relationship between science and theism in general.

This might seem puzzling. Insensitivity is typically linked with unreliability: if the process that produces a belief is insensitive to the truth of that belief, it seems reasonable to conclude that it is an unreliable process at producing beliefs of that kind. How could it be that learning the truth of $\mathrm{S}$ results in insensitivity and yet does not undermine belief in $\mathrm{T}$ via explaining away? The reason for this is that although there is a dependence between $\mathrm{T}$ and $\mathrm{E}$, it is mediated via $S$. Once the truth of $S$ is taken into account, it is $S$ rather than $E$ that is dependent on $\mathrm{T}$ and essentially this means that it is now $\mathrm{S}$ that is sensitive to the truth of $\mathrm{T}$.

This raises a question about the importance of insensitivity. Suppose God creates a process that generates beliefs in supernatural agents. If we imagine the very same process, but in a universe where there are no supernatural agents but otherwise everything is the same, then it will presumably still generate beliefs in supernatural agents. The process will be insensitive since it will result in the same beliefs whether God exists or not, but how is this relevant since, in fact, God created the process? The important question is not whether the process is insensitive, but whether the process would be likely to exist in the absence of God's existence. Ultimately, the question is whether the process undermines belief in supernatural agents given the existence of such beliefs. In other words, it is a question about whether explaining away occurs.

Consider an analogy. Suppose I receive an email from my friend telling me that he will meet me for lunch at $1 \mathrm{pm}$ and so I come to hold that belief. It is indeed true that if I had somehow received the very same email, but it had not been sent by my friend, I would still have come to hold the same belief. Clearly, my belief is insensitive to the origin of the message, but that 
is not relevant. What is relevant is how likely I am to receive such a message if it had not been sent by my friend. ${ }^{22}$

Suppose, however, that God creates a process that does not simply generate beliefs in supernatural agents, but instead enables me to detect whether they exist. If the very same process were to generate beliefs in supernatural agents even if they did not exist, insensitivity would be more of an issue and could lead to explaining away. Even then, we would need to consider other factors such as whether the process would be more likely to exist given God's existence in order to determine whether explaining away actually occurs.

A possible objection to the line of reasoning presented here is that it is not the fact (if it is a fact) of insensitivity, but the awareness of insensitivity, in the absence of independent reasons for belief in God, that presents a problem for the theist. As we shall see below, however, even if one accepts the insensitivity claim, further reasons are needed for thinking that explaining away occurs even in the absence of other reasons for belief in God.

\section{Does Explaining Away Occur?}

According to the independence model (model 1), $\mathrm{T}$ is probabilistically irrelevant to both $\mathrm{S}$ and $\mathrm{E}$. We have already raised questions about the adequacy of this model in general, but it seems particularly weak in the current context since $\mathrm{E}$ is concerned with religious beliefs. Even if it can be argued that $\mathrm{T}$ is probabilistically irrelevant to the sort of evidence that supports scientific theories in general, this seems much less plausible when the evidence in question concerns beliefs about T. Arguably a more plausible approach in the spirit of model 1 might be to say that $\mathrm{E}$ depends on $\mathrm{T}$, but that $\mathrm{S}$ is independent of $\mathrm{T}$ and $\mathrm{E}$. In other words, science cannot explain religious belief and so CSR is a non-starter. However, even if one is suspicious about aspects of the explanations offered by CSR, this move is much too sceptical. For this reason, model 1 and this variant of it will not be considered further.

Before discussing the other model which presupposes the insensitivity claim (model 2), let us consider the indirect conflict model (model 3). According to this model, $\mathrm{T}$ and $\mathrm{S}$ both have a direct influence on $\mathrm{E}$, but there is no direct influence of $\mathrm{T}$ on $\mathrm{S}$. First, let us suppose that the insensitivity claim does in fact hold, $\mathrm{P}(\mathrm{E} \mid \mathrm{T} \& \mathrm{~S})=\mathrm{P}(\mathrm{E} \mid \sim \mathrm{T} \& \mathrm{~S})$. Would this result in explaining away? The condition for explaining away is given by (2). Assuming that in the absence of any acceptable CSR account, T would make E more likely, i.e. $\mathrm{P}(\mathrm{E} \mid \mathrm{T} \& \sim \mathrm{S})>\mathrm{P}(\mathrm{E} \mid \sim \mathrm{T} \& \sim \mathrm{S})$, then the condition for explaining away would be met. Hence, granting the truth of $\mathrm{S}$, or even evidence in favour of $\mathrm{S}$, and the insensitivity claim, this would lead to explaining away.

So although insensitivity and explaining away are distinct, they are closely related in model 3 so that essentially whether explaining away occurs amounts to asking whether the insensitivity claim holds. Unlike models 1 and 2, it does not necessarily hold in this model. Whether it holds depends essentially on whether T adds anything to the account of $\mathrm{E}$ provided by S. Murray and Schloss argue that things might have been very different if God does not exist (and hence $\mathrm{T}$ is false). ${ }^{23}$ For example, it may well be that in the absence of God 
there would be no physical universe or no fine-tuning of the universe and so no intelligent beings with beliefs in supernatural agents, i.e. E would be false. If this is used in response to the insensitivity claim, however, it faces a problem, as both Thurow and Braddock point out. The insensitivity claim is concerned not simply with whether beliefs in supernatural agents would occur in the absence of any supernatural agents, but whether they would occur in the absence of supernatural agents if the processes specified in $S$ were still in operation. This relates to the probability $\mathrm{P}(\mathrm{E} \mid \sim \mathrm{T} \& \mathrm{~S})$. In the last sub-section, the importance of the insensitivity claim was questioned, but it is still relevant in determining whether explaining away occurs, particularly for model 3.

Another possible objection to the insensitivity claim is that $\mathrm{T}$ may contribute to the occurrence of E, perhaps by God's guiding the processes specified in $S$ to bring about $\mathrm{E}$ (or some subset of E relating to monotheistic beliefs). Matthew Braddock objects to this move on the grounds that it is question-begging since the guidance belief presupposes reliability of the belief in supernatural agents. ${ }^{24}$ Given that the guidance claim amounts to the probabilistic claim that $\mathrm{P}(\mathrm{E} \mid \mathrm{T} \& S)>\mathrm{P}(\mathrm{E} \mid \sim \mathrm{T} \& \mathrm{~S})$, and so contradicts the insensitivity claim, it does not require the belief that God guides the relevant processes, but that if God exists (or more generally, if $\mathrm{T}$ is true), then $\mathrm{E}$ (or some subset thereof) would be more likely to occur. In response to Braddock's objection, this means that it does not presuppose the reliability of belief in supernatural agents, but would be based on reasoning about what God (or other supernatural agents) would be likely to do. If such a case can be made, it would provide a reason for doubting the claim that such belief is unreliable. ${ }^{25}$

While questioning the insensitivity claim by appealing to guidance or in other ways might be an option, the goal is not to defend any of these approaches here. Suffice it to say that insofar as a case for insensitivity can be made, it does have scope for explaining away within model 3. This is not surprising since, as we saw in the last section, the indirect conflict model has most scope for explaining away to occur in general. It is also a very questionable model of the relationship between science and theism.

Consider now the conditional independence model (model 2) and recall from the earlier discussion that it presupposes insensitivity. According to this model, explaining away will occur if $\mathrm{S}$ is negatively dependent on $\mathrm{T}, \mathrm{P}(\mathrm{S} \mid \mathrm{T})<\mathrm{P}(\mathrm{S})$, but not otherwise. This is where the response of Murray and Schloss seems more relevant. If God does not exist (and hence $\mathrm{T}$ is false), it may well be that there would be no physical universe or no fine-tuning or no life, and so no CSR processes, and hence S would be false. In other words, Murray and Schloss' response would be relevant, not to the insensitivity claim, but to whether explaining away occurs.

Several objections to the sort of strategy suggested by Murray and Schloss can be made. Most obviously, the suggestion that there might be a positive dependence between $\mathrm{S}$ and $\mathrm{T}$ could be disputed. It seems to rest on contested claims of natural theology pertaining to whether a physical, fine-tuned universe with intelligent life would be more likely to exist given the existence of God. However, the onus is not on the critics of explaining away to establish a 
positive dependence of $\mathrm{S}$ on $\mathrm{T}$, but on its proponents to establish a negative dependence if an argument for explaining away is to be made.

Appeals to natural theology could also give rise to another objection. Recall that debunking arguments are primarily concerned with religious beliefs that are held in a basic, noninferential way and so insofar as this response depends on natural theology it deviates from that position. In response, it can be noted that this highlights the limitation of debunking arguments since religious believers need not be restricted to thinking about their beliefs in non-inferential terms. Moreover, even someone who adopts this non-inferential position could still reason about what the universe would be expected to be like given God's existence or the absence of God's existence. The point would not be to justify belief in God's existence on the basis of such reasoning, but it could be used to address potential defeaters of their beliefs as in the current context. This is particularly relevant here since the onus is on the proponent of explaining away to establish negative dependence between $\mathrm{S}$ and $\mathrm{T}$. If this cannot be established, there is no good reason to think that explaining away occurs.

The interdependence model (model 4) is a hybrid of models 2 and 3, and so the issues discussed in relation to those models are also relevant to it. If the insensitivity claim holds, that could enhance the prospects for explaining away, but even if that is the case a positive dependence between $\mathrm{S}$ and $\mathrm{T}$ could outweigh it. Again, it would not be necessary to establish a strong positive dependence in order to respond to the claim that explaining away occurs. It would only need to be maintained that the sorts of arguments that might be offered in favour of positive dependence between $\mathrm{S}$ and $\mathrm{T}$ are sufficient to compensate for arguments that might be offered for insensitivity.

In summary, the independence model (model 1) does not seem like an appropriate model to adopt in the context of CSR. The conditional independence model (model 2) offers a straightforward way to respond to debunking arguments. It presupposes the insensitivity claim, but avoids explaining away unless it can be shown that there is a negative dependence between $\mathrm{S}$ and T. Since various arguments of natural theology would be relevant to this question, it is difficult to see how explaining away could be established in this case without refuting these arguments. Not surprisingly, as in the general context of explaining away arguments, the indirect conflict model (model 3) offers the best prospects for an explaining away argument to succeed in the context of CSR. If it can be shown that the insensitivity claim is correct, then it seems likely that explaining away would occur if this model is adopted. Finally, the interdependence model (model 4) combines aspects of models 2 and 3. Like model 3, it does provide some scope for explaining away, but like model 2 it also has resources to avoid it.

\section{Discussion}

So far $\mathrm{E}$ has been taken to be a general belief in the existence of supernatural agents. If $\mathrm{E}$ is taken to include more specific religious beliefs, it can affect parts of the argument. For example, whether God might guide the processes involved in CSR could be affected by what 
the target belief is. Furthermore, it is also relevant to how people go about forming their beliefs. As Joshua Thurow argues, if Christian belief is considered, people might cite a variety of reasons in its favour such as the world seeming to be designed, religious experiences, answers to prayer, having witnessed a miracle, evidence relating to early Christianity and the resurrection of Jesus. ${ }^{26} \mathrm{He}$ accepts that CSR shows that if humans lacked these kinds of reasons, it is likely we would still have some sort of religious beliefs. However, to show that people's religious beliefs are unjustified, he argues that it would be necessary to show that the processes they actually use are unreliable and that would require showing that the kinds of reasons cited above are unjustified. His point is that such a conclusion could not be established by CSR, but only by assessing the reasons in question.

This point is certainly relevant to the question of explaining away. Provisionally, it was accepted that some CSR belief account is correct (S), but if the processes considered in CSR fail to include important processes involved in the production of religious belief, then $\mathrm{S}$ could be called into question and that would clearly be detrimental to explaining away.

Alternatively, S could be accepted, but would now only account for some of the relevant evidence excluding the existence of the kinds of reasons for belief noted by Thurow. As such, $\mathrm{S}$ would have no scope to explain away $\mathrm{T}$ insofar as it fails to account for the additional evidence.

The focus so far has been on debunking arguments based on insensitivity, but Matthew Braddock has proposed a novel argument from false gods. Basically, the idea is that we should suspend judgment in the reliability of CSR mechanisms because they give rise to a large percentage of false god beliefs. While a detailed response to his argument is beyond the scope of this article, several points can be made. As noted earlier, Braddock makes it clear that his argument applies to religious beliefs that are formed in a basic, non-inferential way. While this strengthens the argument, it reduces its scope and, like the insensitivity arguments, means that an obvious way to respond to it is by offering reasons for belief in God or other religious beliefs. Some other points brought up in response to insensitivity arguments are also relevant. For example, if the CSR mechanisms appealed to are more likely to occur in a theistic universe than an atheistic one, this could compensate for any undermining of theism that might be thought to occur, just as in explaining away arguments.

The points that follow assume, as Braddock does, the legitimacy of taking belief in God to be basic, at least provisionally. Let us grant the conclusion of the first stage of Braddock's argument: that we should suspend judgment about the reliability of CSR mechanisms with respect to god beliefs. Braddock addresses an objection due to Leech and Visala ${ }^{27}$ that although CSR mechanisms may be unreliable, they comprise only part of the full causal pathway leading to belief in supernatural agents and so the complete belief-forming process may still be reliable. He responds by arguing that CSR mechanisms are significant contributors to god beliefs (premise 7) and that

if we should suspend judgment about the reliability of significant contributors to a belief-forming process $\mathrm{P}$ with respect to a class of beliefs $\mathrm{C}$, and we have no good 
reason to think other significant contributors would confer reliability upon $\mathrm{P}$ with respect to $\mathrm{C}$, then we should suspend judgment about the reliability of $\mathrm{P}$ with respect to C" (premise 8)

Those who consider religious belief to be basic and non-inferential typically claim that if there is a God, belief in God is likely to be warranted in a basic way, but that if there is no God, belief in God is likely not to be warranted in a basic way. Since they consider God to be an indispensable factor in the reliability of the process and yet CSR mechanisms exclude God, they might argue that CSR is irrelevant to their position. Granting premise (7) of Braddock's argument, this means that premise (8) could be questioned. That is, granting that CSR mechanisms are a significant contributor to the belief forming process, suspending judgment about their reliability would not require suspending judgment about the beliefforming process since its reliability was not attributed to CSR mechanisms in the first place. ${ }^{28}$ Would good reasons not need to be given for thinking that other significant factors would confer reliability as Braddock requires? This would seem to be required if the reliability of the belief is attributed to CSR mechanisms, but if it is not, then it is difficult to see why suspending judgment about their reliability would require such reasons to be provided.

Essentially, this means that premise (8) would need to be modified to replace 'we have no good reason to think other significant contributors would confer reliability' with 'we have good reason to think no other significant contributors would confer reliability'. In principle, perhaps CSR could provide support for this claim if it could be shown that all the beliefforming processes could be accounted for by CSR mechanisms. However, Thurow's point about the sorts of reasons cited in favour of particular religious beliefs, such as Christian beliefs, suggests that CSR mechanisms are only part of the causal pathway and leave out potentially important components that might confer reliability. Whether these other components are reliability-conferring is not something that can be established by CSR.

It might be argued that the sorts of factors cited by Thurow are irrelevant to Braddock's argument since it is concerned with beliefs formed in a non-inferential way. However, insofar as these factors are used by religious believers, it could be argued that CSR mechanisms fail to account for all the relevant evidence about the belief-forming process. Braddock considers testimony as a potential mechanism that could confer reliability with respect to religious beliefs, but then asks where the beliefs of the original testifiers come from. He argues that if CSR mechanisms plausibly contributed to their beliefs and if we are not aware of any other factors that could plausibly have conferred reliability, then we should doubt the reliability of their beliefs. While this response seems reasonable for some types of religious belief where CSR mechanisms may well account for all the relevant evidence, it seems much less plausible if one is considering, for example, the historical origins of Christian belief. One could certainly doubt that CSR mechanisms are all that relevant when dealing with such historical contexts and also provide reasons for thinking that the testimonial evidence is reliable. Such reasons could call into question premise (9) of Braddock's argument, that "we have no good reason to think other significant contributors to our belief-forming processes would confer reliability upon them with respect to the class of god beliefs." ${ }^{29}$ This premise 
could be questioned even by those who hold a non-inferential approach to religious belief. According to this view, such reasons would not be considered necessary to justify the religious beliefs in question, but may well be sufficient to respond to debunking arguments based on CSR. ${ }^{30}$ Whether or not the testimonial evidence in question is reliable, the point is that it is very doubtful that appealing to CSR mechanisms is the right way to proceed.

\section{Conclusion}

Explaining away has been investigated in CSR, particularly in the context of a debunking argument against theism based on the insensitivity of the processes that give rise to theistic beliefs. To provide an appropriate framework, previous work on explaining away was reviewed and then a number of models of the relationship between science and theism were considered in terms of their relevance to explaining away arguments.

In terms of the debunking argument, a number of points can be made in summary. It is not immediately clear that the argument avoids the charge of committing the genetic fallacy. Most plausibly, it can be construed as targeting theistic beliefs formed in a basic and noninferential way, but this invites the obvious response that there are many reasons for belief in God which need to be evaluated on their own terms rather than by appealing to CSR explanations of religious belief. Furthermore, since many believers do appeal to reasons for their beliefs it is very doubtful that CSR can explain all the relevant evidence and, a fortiori, very doubtful that explaining away arguments even get off the ground.

Even if these concerns are set aside, it is still not clear that explaining away arguments are likely to be successful. An important point is that the insensitivity claim must be distinguished from that of explaining away. In particular, even if the insensitivity claim is true, it does not follow that CSR mechanisms explain away theistic beliefs. In light of the four models of the relationship between science and theism, by far the most plausible case for explaining away occurs in the indirect conflict model, which the theist has good reason to reject in any case. In the two plausible models, there are plenty of resources for the theist to avoid explaining away. Overall, the prospects for explaining away of religious belief from CSR seem very limited.

\section{Acknowledgments}

This publication was made possible through the support of a grant from the John Templeton Foundation (grant number 40676). The opinions expressed in this publication are those of the author and do not necessarily reflect the views of the John Templeton Foundation. The author would like to thank Matthew Braddock for providing very helpful comments. 


\title{
Biographical Note
}

\author{
David H. Glass is a Senior Lecturer in the School of Computing and Mathematics at Ulster \\ University.
}

\section{Endnotes}

${ }^{1}$ M.P. Wellman and M. Henrion, "Explaining "Explaining Away," IEEE Transactions on Pattern Analysis and Machine Intelligence 15 (1993), 287-292; David H. Glass, “Can Evidence for Design Be Explained Away?,” in Probability in the Philosophy of Religion, ed. J. Chandler and V. Harrison (Oxford: Oxford University Press, 2012), 79-102.

${ }^{2}$ David H. Glass and Mark McCartney, "Explaining and Explaining Away in Science and Religion," Theology and Science 12 (2014), 338-361.

${ }^{3}$ Rodney D. Holder, "Explaining and Explaining Away in Cosmology and Theology," this volume.

${ }^{4}$ For further details see Glass, "Can Evidence for Design Be Explained Away?" and Glass and McCartney, "Explaining and Explaining Away in Science and Religion."

${ }^{5}$ In previous work a distinction was made between partial, complete and absolute explaining away. As used here, explaining away will occur if any of these three types occurs.

${ }^{6}$ This account differs from that provided by Jonah N. Schupbach, "Competing Explanations and ExplainingAway Arguments," this volume. Essentially, the difference is that Schupbach's account focuses on the indirect pathway whereas in the current work both the indirect and direct pathways are taken into account. Schupbach's account has the advantage that the indirect pathway is indeed more closely related to explaining away. However, in order to determine whether explaining away occurs, it does seem necessary to take into account the influence along both pathways. For example, if there is a negative influence between the hypotheses via the indirect pathway that is outweighed by a positive influence along the direct pathway, it seems right to say that explaining away does not occur.

${ }^{7}$ See John L. Pollock and Joseph Cruz, Contemporary Theories of Knowledge, 2nd Ed. (Lanham, MD: Rowman \& Littlefield, 1999).

${ }^{8}$ In another paper, a Bayesian approach is used to define degrees of rebutting and undercutting defeat corresponding to the direct and indirect pathways involved in explaining away and the related notion of hypothesis competition, see David H. Glass and Jonah N. Schupbach, "When do hypotheses compete?" (unpublished manuscript, 2016).

${ }^{9}$ Ian G. Barbour, Religion in an Age of Science (New York: HarperCollins, 1990).

${ }^{10}$ See, for example, Judea Pearl, Probabilistic Reasoning in Intelligent Systems (San Francisco: Morgan Kaufman, 1988)

${ }^{11}$ As pointed out in note 5, this could be partial explaining away, in which case there would still be reason to accept $\mathrm{T}$ based on $\mathrm{E}$.

${ }^{12}$ It might seem puzzling that bringing God's guidance into the picture in model 4 allows more scope for explaining away than model 2. The reason for this is because it also allows for additional support of theism and hence the probability of theism given the evidence, $\mathrm{P}(\mathrm{T} \mid \mathrm{E})$, might be higher in model 4 than it would be in model 2. This means that even if explaining away does occur to some extent in model 4 it might be less important because the overall probability of theism given both science and the evidence, $\mathrm{P}(\mathrm{T} \mid \mathrm{S} \& \mathrm{E})$, may well be greater in model 4 than in model 2.

${ }^{13}$ See Justin Barrett, "Cognitive Science of Religion: What Is It and Why Is It?," Religion Compass 1 (2007), 768-786; Pascal Boyer, Religion Explained: The Evolutionary Origins of Religious Thought (New York: Basic Books, 2001); Scott Atran, In Gods we Trust: The Evolutionary Landscape of Religion (Oxford: Oxford University Press, 2002).

${ }^{14}$ See, for example, Jeffrey Schloss and Michael J. Murray (eds.) The Believing Primate (New York: Oxford University, 2009); Joseph Bulbulia, "Bayes and the Evolution of Belief," in Debating Christian Theism, ed. J.P. Moreland, C. Meister and K.A. Sweis (New York: Oxford University Press, 2013), 223-241; Matthew

Braddock, "Debunking Arguments and the Cognitive Science of Religion," this volume.

${ }^{15}$ Guy Kahane, "Evolutionary debunking arguments," Noûs 45 (2011), 103-125.

${ }^{16}$ Joshua C. Thurow. "Does Cognitive Science Show Belief in God To Be Irrational? The Epistemic Consequences of the Cognitive Science of Religion," International Journal for Philosophy of Religion 74 (2013), 77-98.

${ }^{17}$ Alvin Plantinga, Warranted Christian Belief (Oxford: Oxford University Press, 2000). 
${ }^{18}$ A reviewer draws attention to the possibility that CSR might be able to account for intuitions that play a role in the arguments of natural theology. While this point should not be ignored, good evidence would need to be presented that it was true, not merely possible, and that it applied to intuitions relevant to a range of theistic arguments. Also, even if it is true, it does not follow that the theistic arguments in question would have no force once insights from CSR have been taken into account or that the arguments could not be reformulated in light of these insights. Finally, the question of the genetic fallacy raises its head again - just because CSR might explain certain intuitions, it does not automatically follow that these intuitions should be rejected.

${ }^{19}$ For further discussion on the genetic fallacy in this context, see Jonathan Jong and Aku Visala, "Evolutionary debunking arguments against theism, reconsidered," International Journal for Philosophy of Religion 76 (2014), 243-258.

${ }^{20}$ See Thurow, "Does Cognitive Science Show Belief in God To Be Irrational?" for further discussion on insensitivity.

${ }^{21}$ This does not mean that we assume that $\mathrm{S}$ makes $\mathrm{E}$ inevitable, $\mathrm{P}(\mathrm{E} \mid \mathrm{S})=1$, but just that the processes identified in $S$ actually occur and contribute to $\mathrm{E}$.

${ }^{22}$ A possible objection to this analogy is that in order to assess insensitivity the belief-forming process must be kept the same, but here it is not because of the friend's causal role in one case but not the other. Two points can be made in response. First, it is not clear that the belief-forming process is different since, by assumption, I receive exactly the same email in exactly the same way; it is the ultimate causal source of the email that differs. Second, if God is the ultimate causal source of belief in supernatural agents, then if a change in the causal source results in a change in the belief-forming process, insensitivity arguments become impossible. Thanks to a reviewer for raising this objection.

${ }^{23}$ Michael J. Murray and Jeffrey P. Schloss, "Evolutionary Accounts of Religion and the Justification of Religious Belief," in Moreland et al., Debating Christian Theism 242-258.

${ }^{24}$ Braddock, "Debunking Arguments and the Cognitive Science of Religion."

${ }^{25}$ Braddock also argues that explanatory considerations suggest that the guidance belief is likely to be false. While this argument will not be evaluated here, it is worth noting that even if it shows that unguided processes would account for the diversity of religious belief in general, this is compatible with God guiding a subset of religious beliefs. Nevertheless, this argument does suggest that appealing to God's guidance of CSR mechanisms may not be an adequate response to debunking arguments.

${ }^{26}$ Thurow, "Does Cognitive Science Show Belief in God To Be Irrational?"

${ }^{27}$ David Leech and Aku Visala, "The Cognitive Science of Religion: A Modified Theist Response," Religious Studies 47(2011), 301-316.

${ }^{28}$ If being a significant contributor to the belief-forming process involves being a significant contributor to its reliability, then premise (7) could be questioned instead.

${ }^{29}$ In any case, if the earlier comment about premise (8) is correct, then premise (9) should be modified to "We have good reason to think no other significant contributors to our belief-forming processes would confer reliability upon them with respect to the class of god beliefs."

${ }^{30}$ Braddock offers a very interesting response to what he calls the Objection from Reformed Epistemology. He argues that unguided explanations of our god beliefs are significantly better than guided explanations. This does seem to raise a legitimate question about appealing to God's guidance of CSR mechanisms as noted earlier. The response being offered here, however, does not appeal to God's guidance, but to mechanisms in addition to those described by CSR. 